Earth Interactions • Volume 15 (2011) • Paper No. 7 • Page 1

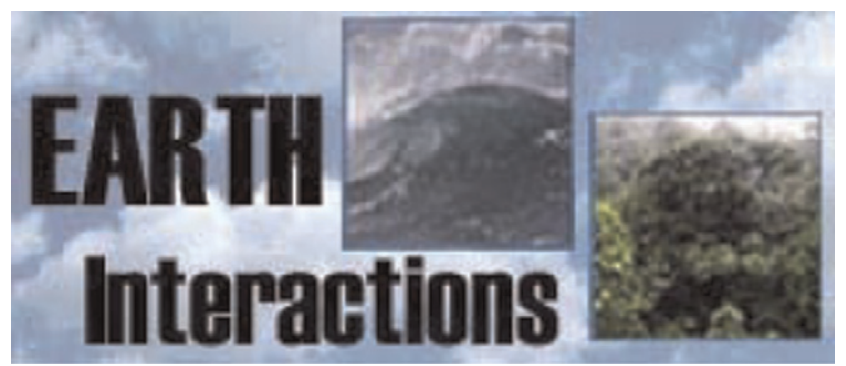

Copyright (C 2011, Paper 15-007; 6158 words, 7 Figures, 0 Animations, 0 Tables. http://EarthInteractions.org

\title{
Land-Cover and Surface Water Change Drive Large Albedo Increases in South America*
}

\section{Scott R. Loarie ${ }^{+}$}

Department of Global Ecology, Carnegie Institution for Science, Stanford, California

\section{David B. Lobell}

Program on Food Security and the Environment, Stanford University, Stanford, California

\section{Gregory P. Asner and Christopher B. Field}

Department of Global Ecology, Carnegie Institution for Science, Stanford, California

Received 20 March 2010; accepted 25 September 2010

\begin{abstract}
Albedo is an important factor affecting global climate, but uncertainty in the sources and magnitudes of albedo change has led to simplistic treatments of albedo in climate models. Here, the authors examine nine years (2000-08) of historical 1-km Moderate Resolution Imaging Spectroradiometer (MODIS) albedo estimates across South America to advance understanding of the magnitude and sources of large-scale albedo changes. The authors use the magnitude of albedo change from the arc of deforestation along the southeastern edge of the Brazilian Amazon ( $+2.8 \%$ ) as a benchmark for comparison. Large albedo increases $(>+2.8 \%)$ were 2.2 times more prevalent than similar decreases throughout South America. Changes in surface water drove most
\end{abstract}

* Supplemental information related to this paper is available at the Journals Online Web site: http://dx.doi.org/10.1175/2010EI342.s1.

${ }^{+}$Corresponding author address: Scott R. Loarie, Department of Global Ecology, Carnegie Institution for Science, 260 Panama St., Stanford, CA 94305.

E-mail address: loarie@ $@$ stanford.edu

DOI: $10.1175 / 2010 \mathrm{EI} 342.1$ 
Earth Interactions • Volume 15 (2011) • Paper No. 7 • Page 2

large albedo changes that were not caused by vegetative cover change. Decreased surface water in the Santa Fe and Buenos Aires regions of Argentina was responsible for albedo increases exceeding that of the arc of deforestation in magnitude and extent. Although variations in the natural flooding regimes were likely the dominant mechanism driving changes in surface water, it is possible that human manipulations through dams and other agriculture infrastructure contributed. This study demonstrates the substantial role that landcover and surface water change can play in continental-scale albedo trends and suggests ways to better incorporate these processes into global climate models.

KEYWORDS: Land-cover change; Albedo; MODIS

\section{Introduction}

Land surface albedo is a major driver of climate change (Bonan 2008; Wielicki et al. 2005), but climate models rarely incorporate projected albedo changes from future land use (Oleson et al. 2003; Tian et al. 2004). This is largely because of a continued poor understanding of the historic drivers of albedo change. Certain land-cover transitions, such as boreal and tropical deforestation, drive relatively well understood albedo changes that have been evaluated in climate studies (Betts 2000; Costa et al. 2007). Less work has documented the importance of albedo changes from other land-cover and land-use processes or relative to climate-induced changes in surface albedo, such as regional flooding or the melting of alpine glaciers (Sicart et al. 2001). A more complete understanding of the patterns and drivers of historic albedo changes would help focus efforts to improve the representation of albedo in climate models (Henderson-Sellers and Wilson 1983).

The Moderate Resolution Imaging Spectroradiometer (MODIS) sensor has routinely estimated surface albedo from space since 2000 and therefore provides a unique dataset with which to assess albedo trends across large geographic areas. Here, we analyzed nine years of data from MODIS at $1-\mathrm{km}$ resolution to examine albedo changes across the continent of South America. South America covers 12\% of the Earth's land surface, contains 10 of the 14 terrestrial biomes (Olson et al. 2001), and is a global hotspot of deforestation (Hansen et al. 2008) and agricultural expansion (Martinelli and Filoso 2008).

We compared albedo data with MODIS reflectance and precipitation data to understand how land-cover change is manifested in albedo changes at large scales. This study focuses on three questions: What are the general patterns of albedo change across the continent over the last decade? Which landscapes underwent the largest albedo changes? What physical changes are responsible for these altered albedos?

\section{Data and methods}

\subsection{Albedo data}

For all 29 of the $1200 \mathrm{~km} \times 1200 \mathrm{~km}$ MODIS tiles that cover South America, we compiled 9-yr time series made up of 414 8-day albedo (MCD43B3 Albedo_ WSA_shortwave, version 5) and albedo quality (MCD43B2 BRDF_Albedo_Quality, version 5) data from 2000-057 (8-day composite beginning on this year-ordinal day) to 2009-049 at 1-km resolution. These time series started several months into 2000. 
Earth Interactions • Volume 15 (2011) • Paper No. 7 • Page 3

To encompass nine years, we therefore define each year-long period beginning on ordinal day 57. For example, we define 2000 as the 46 data points from 2000-057 through 2001-049.

\subsection{Albedo change and uncertainty}

To quantify changes in albedo within each pixel, we grouped the time series by year and fit linear regression slopes for the 9-yr period. Validation studies have reported root-mean-square errors in the MODIS albedo product of 1.7\% (Liang et al. 2002) and 1.8\% (Jin et al. 2003). To test how much this error influences albedo trends, we simulated 10000 albedo time series with means of $12 \%$ and standard deviations of $1.8 \%$. The probability of such error producing artificial trends steeper than $0.6 \%$ is less than 0.05 (supplementary Figure S1).

Because errors may not be randomly distributed but rather correlated with certain times of year and regions, we performed a second uncertainty comparing maps of change produced using all data with maps produced using only good quality data. To product the latter, we used the albedo quality product. For each of the 1.44 million grid cells in a tile, the albedo quality product describes the overall quality of the albedo product summarized as good quality data, bad quality data, and no data (see supplementary Figure S2). These quality flags summarize atmospheric effects across all bands from both the Terra and Aqua satellites used to calculate the albedo product. At each point in the time series, we calculated the percentage of good quality data from the total dataset. We fit a smoothed spline through this percentage overlapping all nine years into a single annual cycle with 46 time slots. We defined the subset of the year with sufficient good quality data as the largest continuous period of time with at least $20 \%$ good quality data (see supplementary Figure S3). We used only this subset each year and considered it to be representative of the entire year. Outside of this good quality subset, the albedo of the land surface is a less relevant driver of climate, as it is dominated by the albedo of the clouds that contribute to the low quality data. Including only this good quality subset, we computed slopes as before.

Because there was an unusually high amount of bad quality data in 2000 and 2001, we also computed maps excluding these first two years. We compared all three albedo change maps (see supplementary Figure S4). In all cases, the resulting albedo maps were very similar, indicating that errors correlated with season or region did not drive the albedo change patterns and magnitudes. We chose the quality-controlled, 9-yr time series for all analyses that follow.

\subsection{Other data}

To develop a better understanding of what land-cover changes drive the patterns of albedo changes, we also compiled 16-day MODIS reflectance data for the study area, which included blue (459-479 nm), red (620-670 nm), near-infrared (NIR; 841-876 nm), and midinfrared (MIR; 2105-2155 nm) reflectance bands at 1-km resolution. Surface water has a distinctive spectra with relatively low reflectance overall and characteristically low MIR, red, and blue reflectance relative to NIR. These relatively low reflected values of shorter-wave infrared (such as MIR) were 
Earth Interactions - Volume 15 (2011) • Paper No. 7 • Page 4

compared with NIR drive high land surface water indices, which have been used as a univariate approach toward surface water detection (Xiao et al. 2006). Over isolated deep-water lakes, such as the Mar Chiquita (Figure 2c, whitish areas in false-color reflectance maps), imperfectly masked clouds result in artificially high reflectance values. Our results, which are drawn from subsets of grid cells undergoing large albedo changes outside of these areas, are not influenced by cloud masking.

Precipitation data were compiled from the Tropical Rainfall Monitoring Mission (TRMM) 3B42 product, which merges calibrated infrared and other satellite measurements to estimate tropical precipitation every $3 \mathrm{~h}$ on a scale of $0.25^{\circ}$ spatial resolution $(\sim 28 \mathrm{~km})$. We sum these data to provide monthly precipitation $(\mathrm{mm})$ across the study area and the 9-yr time period.

The arc of deforestation along the southeastern edge of the Brazilian Amazon has been well studied (Morton et al. 2006). As a result, the drivers of albedo change are known to be human-caused deforestation (Costa et al. 2007) and regional-scale PRODES data describing patterns of deforestation are available. These features make albedo changes in the Brazilian Amazon arc of deforestation an appealing benchmark for comparing less well-known changes. To do this, we collected the Brazilian Space Research Institute's Programa Despoluição de Bacias Hidrográficas (PRODES) annual deforestation summaries, which identify specific areas deforested each year from 2000 through 2007 (INPE 2009). We reclassified these maps into nonforested land, land deforested before 2000, land forested in 2008, and land deforested in each intervening year. We then overlaid these data with MODIS albedos in the arc of deforestation in Mato Grosso (Figure 1a, red rectangle) and extracted albedos from 5037 MODIS cells where more than $50 \%$ of the area in each cell was deforested in 2004. The albedo time series of these cells (Figures 1d-f) was then used to calculate a regression slope, which we used to define "large albedo changes" relative to Brazilian Amazon deforestation for the following analysis.

\subsection{Large albedo changes}

To understand which landscapes underwent the largest albedo changes, we selected all grid cells with albedo changes greater than or equal to the absolute value of the large albedo change defined above. We summarized these changes within several regions of interest that were defined subjectively after examining the albedo change map. Defining these regions, we sought to cover a large proportion of the albedo changes in a small number of regions where exemplary processes driving the change were relatively homogeneous across the region. Space prevents treating each dam and agricultural field separately. However, after excluding areas with scarce $(<10 \%)$ good quality data, we were able to encompass $79 \%$ and $43 \%$ of remaining large albedo increases and decreases within eight regions of interest.

\section{Results}

\subsection{General patterns of albedo change across the continent}

Over the last nine years, there have been significantly more albedo increases across South America than decreases ( $t$ test; $p \ll 0.001$; Figure 1a). The average 


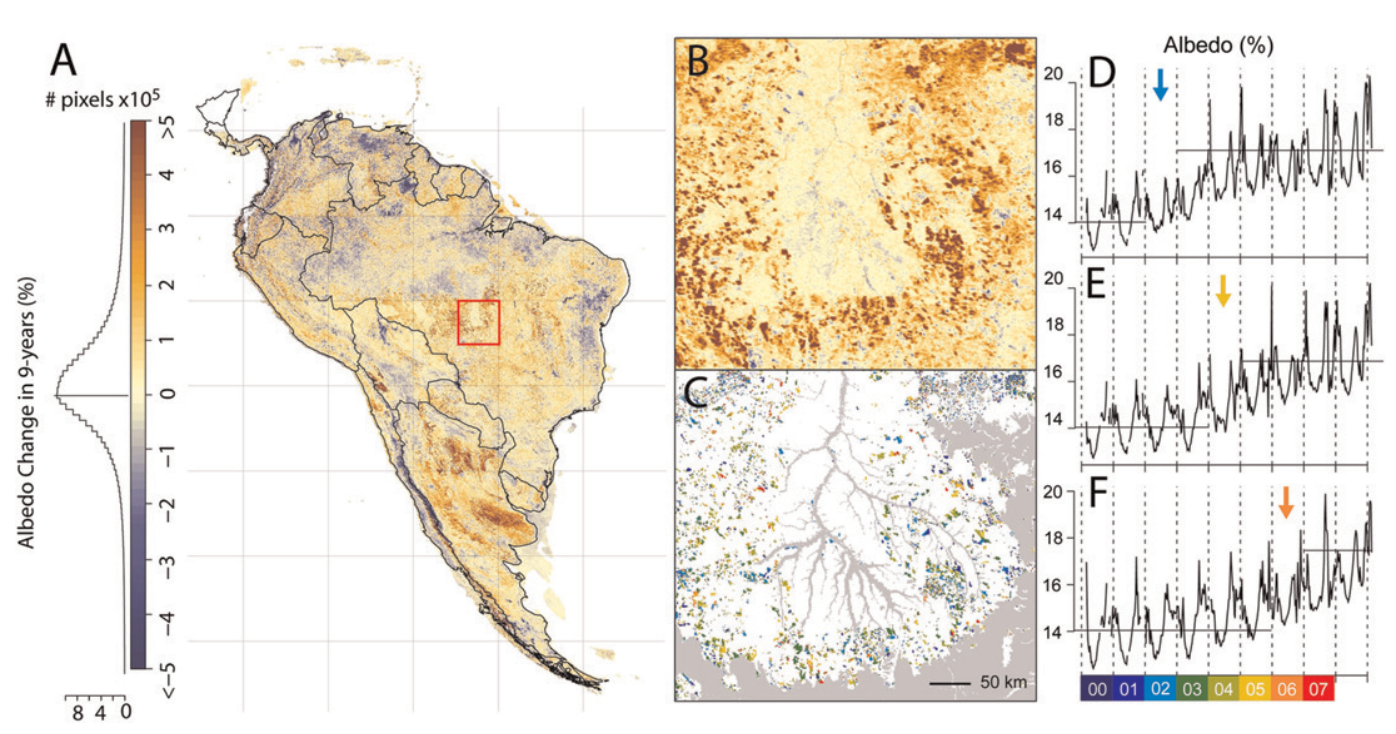

Figure 1. (a) Albedo change (\%) over a 9-yr period (2000-08) across South America calculated from 1-km, 8-day MODIS albedo products. The histogram corresponds to the color bar. Black outlines are country boundaries. Red rectangle overlaps the state of Mato Grosso in the southern Brazilian Amazon (northeast quarter of tile $\mathrm{h} 12 \mathrm{v} 10$ ). A detail of this quarter tile showing (b) albedo change from 2000 to 2007 and (c) PRODES deforestation data colored by deforestation year. Areas not naturally forested are in gray. Graphs show albedo (\%) for 1-km pixels deforested in (d) 2002, (e) 2004, and (f) 2006. Arrows indicate year deforested, and horizontal lines show average albedo before and after deforestation.

change was $0.25 \%$ over nine years $\left(0.028 \% \mathrm{yr}^{-1}\right.$; see supplementary Figure S5 for albedo summary maps from 2000 to 2002 and from 2006 to 2008).

\subsection{Albedo increases and Amazon deforestation}

Calculated from the subset of grid cells deforested in 2004, the average albedo for intact forest two years before deforestation was $14.0 \%$ and the average albedo two years after deforestation was $16.8 \%$. The albedo change during this period was $2.8 \%$ points (Figure 1e). These magnitudes were comparable with grid cells deforested in 2002 and 2006 (Figures 1d,f). Two years after the deforestation event, the albedos appear to stabilize (Figures 1d-f).

\subsection{Large albedo changes summarized by regions of interest}

We mapped all areas that have undergone albedo increases or decreases greater than or equal to $2.8 \%$, the magnitude associated with tropical deforestation (Figure 2). Large albedo increases were 2.2 times as abundant as large decreases. Moreover, $25 \%$ of large increases and $51 \%$ of large decreases fall in areas with scarce good quality data $(<10 \%$; Figure 2 , dark gray areas). When these areas were excluded, 


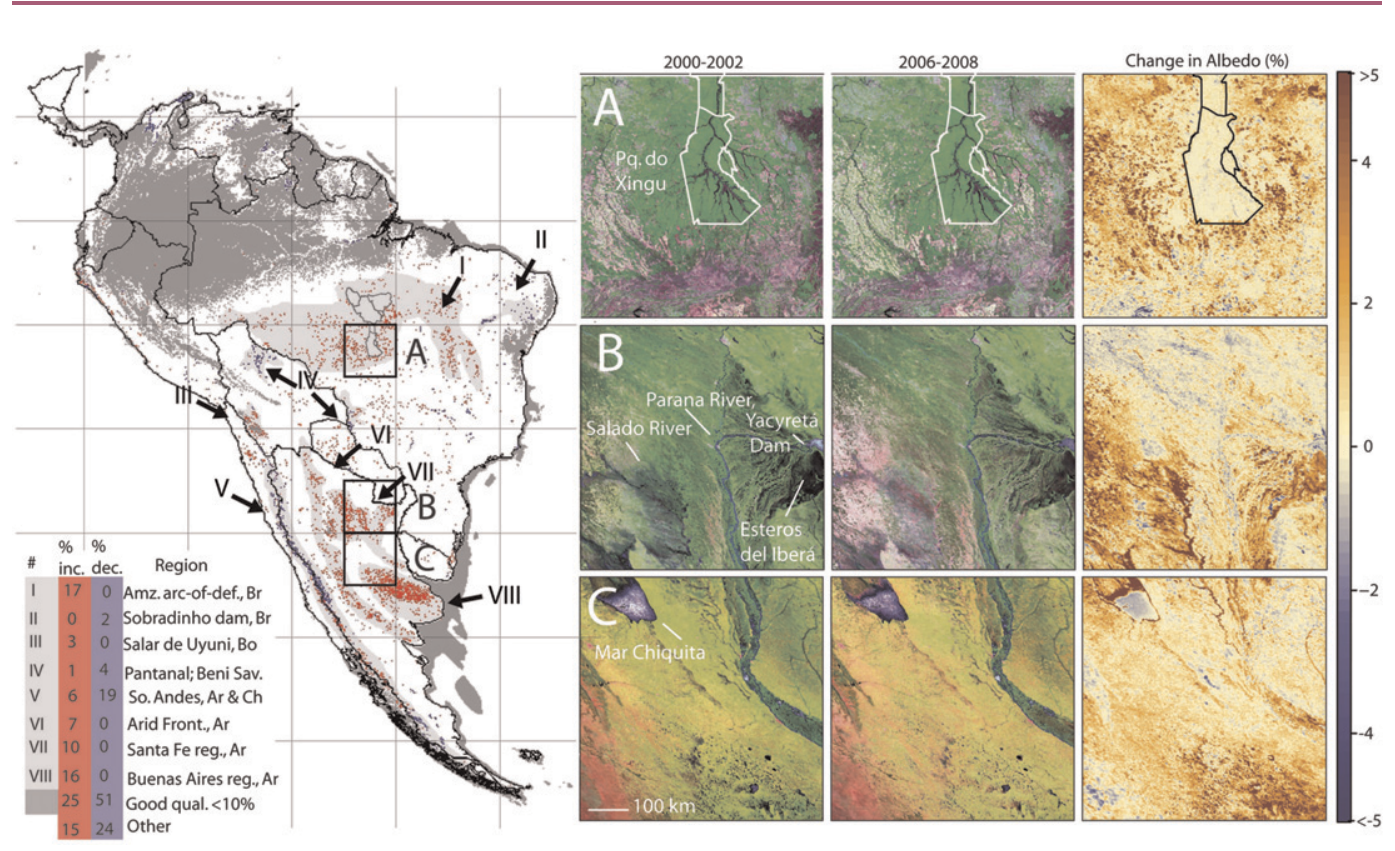

Figure 2. Large increases ( $>+2.8 \%$; red) and decreases $(<-2.8 \%$; blue) in albedo across South America. The legend shows the percentage of these large changes within regions of interest (light gray areas) labeled by roman numerals. Dark gray areas have scarce good quality data $(<10 \%)$. Black outlines are country boundaries. Gray outlines indicate a sample of indigenous reserves in Brazil, including the Parque Nacional Indigena do Xingu. The gray grid shows $1200 \mathrm{~km} \times 1200 \mathrm{~km}$ MODIS tiles. (a)-(c) Quarter MODIS tiles that intersect three regions of interest. Columns represent composite false-color images of reflectance averaged across 2000-02 and 2006-08 and change in albedo over the 9-yr period. False color represents the MIR, NIR, and red reflectance with red, green, and blue colors, respectively. Under this scheme, vegetation appears green, water appears blue, and bare ground appears pink. In the false-color maps, whitish colors over deep-water areas such as Mar Chiquita result from imperfect cloud masking in the MODIS monthly reflectance product. (right) The blue to red color scheme in the maps represents change in albedo. Outlines in the Amazon arc-of-deforestation image indicate the Parque Nacional Indigena do Xingu. Labels in the Argentina images indicate water bodies referred to in the text.

large increases become 4.6 times as abundant as large decreases. Figure 2 summarizes these large increases and decreases by several regions of interest. Large decreases were most common (19\%) in the Southern Andes (Figure 2, region V), flooded grasslands and savannas (e.g., $4 \%$ occurred in the Pantanal and Beni Savanna, region IV), and regions surrounding dams (e.g., $2 \%$ occurred near the Sobradinho Dam in Brazil, region II).

Only $17 \%$ of large albedo increases were associated with the Amazon arc of deforestation, including northern forested regions of the Cerrado (Figure 2, region I). A westward-facing arc in the Argentinan Chaco (Figure 2, region VI) accounted 
Earth Interactions • Volume 15 (2011) • Paper No. 7 • Page 7

for $7 \%$ of albedo increases. Two other areas in Argentina, the Santa Fe province around the Parana and Salado Rivers (Figure 2, region VII) and the humid Pampas in the Buenos Aires province (Figure 2, region VIII), accounted for $10 \%$ and $16 \%$ of large albedo increases, respectively. Additionally, the Southern Andes (Figure 2, region $\mathrm{V}$ ) accounted for $6 \%$ of large albedo increases. Large albedo increases were often associated with salt flats. As an example, the world's largest salt flat, the Salar de Uyuni in Bolivia (Figure 2, region III), accounted for 3\% of large albedo increases. These increases are likely driven by decreases in the length of time that these salt flats are covered by surface water.

Excluding areas with scarce good quality data and the Southern Andes, where seasonal snow cover makes this region prone to cloud-masking errors (Hall and Riggs 2007), three areas had particularly large concentrations of large albedo changes. These areas were the Amazon arc of deforestation in Brazil, the Santa Fe region of Argentina, and the Buenos Aires region of Argentina. In all three regions, albedo increases dominate.

\subsection{Case studies of large albedo changes}

We selected three MODIS quarter tiles that intersect the Amazon arc of deforestation, Brazil; the Santa Fe region, Argentina; and the Buenos Aires region, Argentina (Figures 2a-c). Noticeable increases in NIR (Figure 2a, light green areas) may result from ongoing transitions to brighter soy crops from cattle pastures or recently cleared and burned areas with dark soils may contribute.

Interestingly, the high NIR of crops (Figure 2a, light green) results in higher albedos than bare ground (Figure $2 \mathrm{a}$, pink areas), likely because of dark soils in this region. In the latter two tiles, MODIS data reveal that albedo increased where surface water was much more extensive in the early part of the time series than in the later part (Figures 2 and 3). There were precipitation decreases $\left(3 \mathrm{~mm} \mathrm{yr}^{-1}\right)$ in these latter two tiles and increases $\left(1 \mathrm{~mm} \mathrm{yr}^{-1}\right)$ in the Amazon arc of deforestation. Although Amazon deforestation results from albedo increase from 14.0\% to $16.8 \%$, the reduction in surface water increased albedo from $12.1 \%$ to $15.8 \%$ from increased NIR and MIR reflectance in the middle part of the year (Figure 3). To quantify the relationship between surface water and albedo in the Buenos Aires region of Argentina (supplementary Figure S6), we identified the extent of surface water using the fifth band of a 30-m Landsat image (path 227, row 84, 25 January 2006) that covered 38630 1-km MODIS kernels. Albedo was well correlated with surface water $\left(R^{2}=0.34\right)$ and varied from $19.4 \%$ to $5.3 \%$ with increasing inundation.

\subsection{Drivers of surface water change}

To explore mechanisms driving changes in surface water, we mapped precipitation change over the region. On average, annual precipitation decreased (change in millimeters: -0.01 mean and 1.12 standard deviation) over the 9 -yr period (Figure 4). This weak correlation could suggest that nonclimatic factors such as human infrastructure have contributed to these changes. In specific locations where the correlation between albedo increases and precipitation is weak, there is evidence 
Earth Interactions • Volume 15 (2011) • Paper No. 7 • Page 8

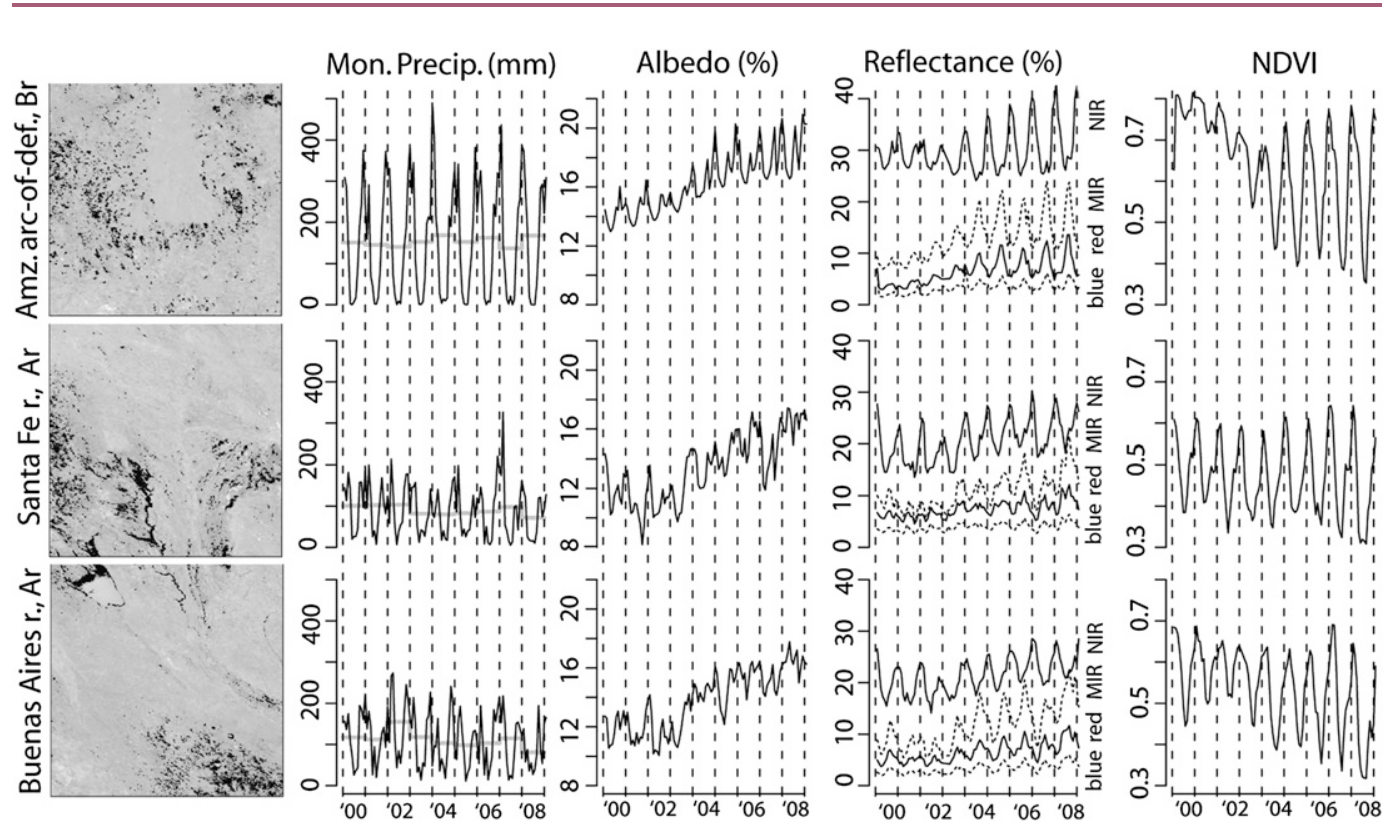

Figure 3. (left) Areas with large $(>2.8 \%$ ) albedo increase in black for the three quarter tiles identified in Figure 2. Shown separately (left-middle)-(right) are 9-yr time series averaged across these black areas for monthly precipitation ( $\mathrm{mm}$ ) from TRMM; albedo (\%) from the MODIS albedo product; reflectance (\%) from MODIS NIR, MIR (dotted line), red, and blue (dotted line) bands; and normalized difference vegetation index (NDVI) calculated from the reflectance. Mean annual precipitation is in gray.

that finescale anthropogenic manipulations to hydrology such as canals might influence the extent and duration of surface water (Figure 5). It is also possible, however, that lags in surface water runoff explain the weak correlations with precipitation. There is a clear need for detailed hydrological models data on finescale anthropogenic manipulations to test these hypotheses and discriminate these drivers.

\subsection{Albedo implications of agricultural expansion in arid landscapes}

Land-cover change in moist tropical forests generally results in albedo increases because agriculture and pastures are brighter than forests. In arid ecosystems, the expansion of agriculture and pastures can result in albedo increases or decreases. For example, in the westward-facing arc in the Argentinan Chaco (Figure 2, region VI), clearing of dark shrubby vegetation for pasture reveals bright soils and drives albedo increases (Figure 6). However, in areas where reservoirs have been utilized for irrigation, the increased availability of perennial water for crops can result in greener landscapes that are less bright, thereby decreasing albedo (Figure 7). Likewise, in some landscape, flushes of darker, greener vegetation drive decreases in albedo (see supplementary Figure S7). It is likely that increases in precipitation drive these changes. 


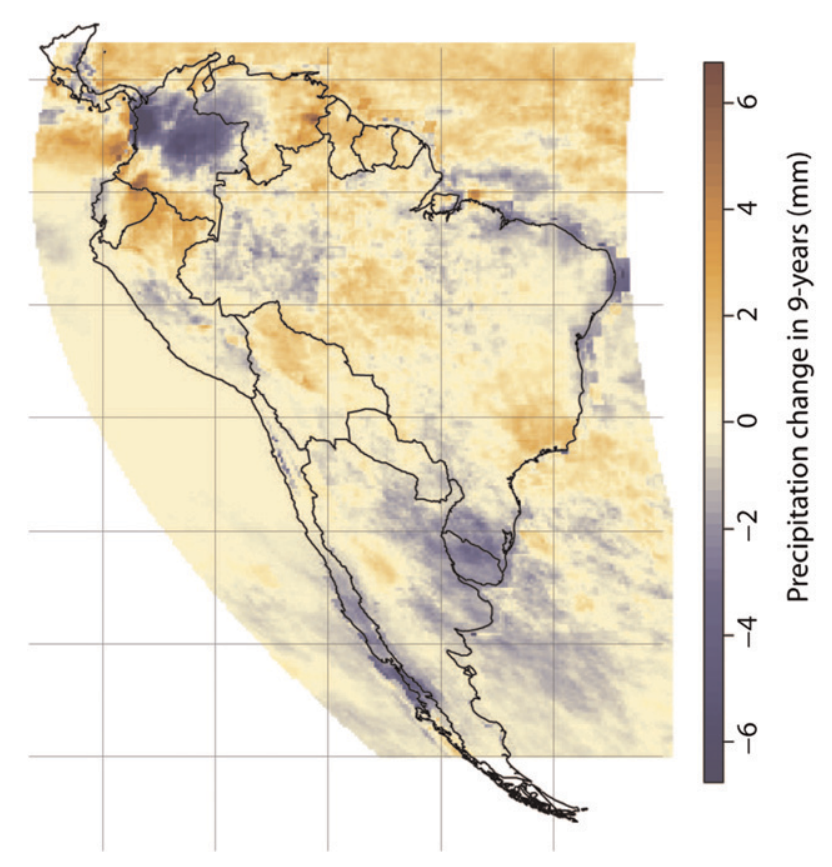

Figure 4. A map of change in total annual precipitation $(\mathrm{mm})$ over a 9-yr period (2000-08) across South America.

\section{Discussion and conclusions}

Over the last nine years, the albedo of the South American continent has increased by about $0.25 \%$. Patterns of change are spatially complex. Large areas to the north of the continent, especially the Northern Andes, were too cloudy to yield enough good quality data for robust calculations. In this paper, we focus on three striking examples of albedo increases that are particularly important in terms of geographic extent and magnitude of change: the Amazon arc of deforestation in Brazil, the Santa Fe region in Argentina, and the Buenos Aires region in Argentina. We were able to describe $61 \%$ of large albedo changes in eight contiguous regions of interest (Figure 2), excluding landscapes with scarce good quality data. Overwhelmingly, the changes fall into two categories: change in vegetation and change in surface water (Otterman 1977).

Land-cover change from darker forests to brighter pasture or agriculture increases albedo (Lambin et al. 2001; Turner et al. 2007). Such land-cover change is most extensive along the Amazon arc of deforestation and in forested parts of the northern Cerrado (Loarie et al. 2009). Land-cover change in more arid landscapes can also lead to large albedo increases (Otterman and Tucker 1985). For example, south of the Amazon, vegetation becomes progressively more arid and a belt of increasingly dry forest and shrub land runs from the Cerrado in Brazil, through Bolivia and Paraguay, and down through Argentina between the Andes to the west and the Pampas and grasslands to the east. Agricultural expansion that clears this dark vegetation to reveal bright soils results in albedo increases that are similar in magnitude to those from deforestation in moist tropical regions. 

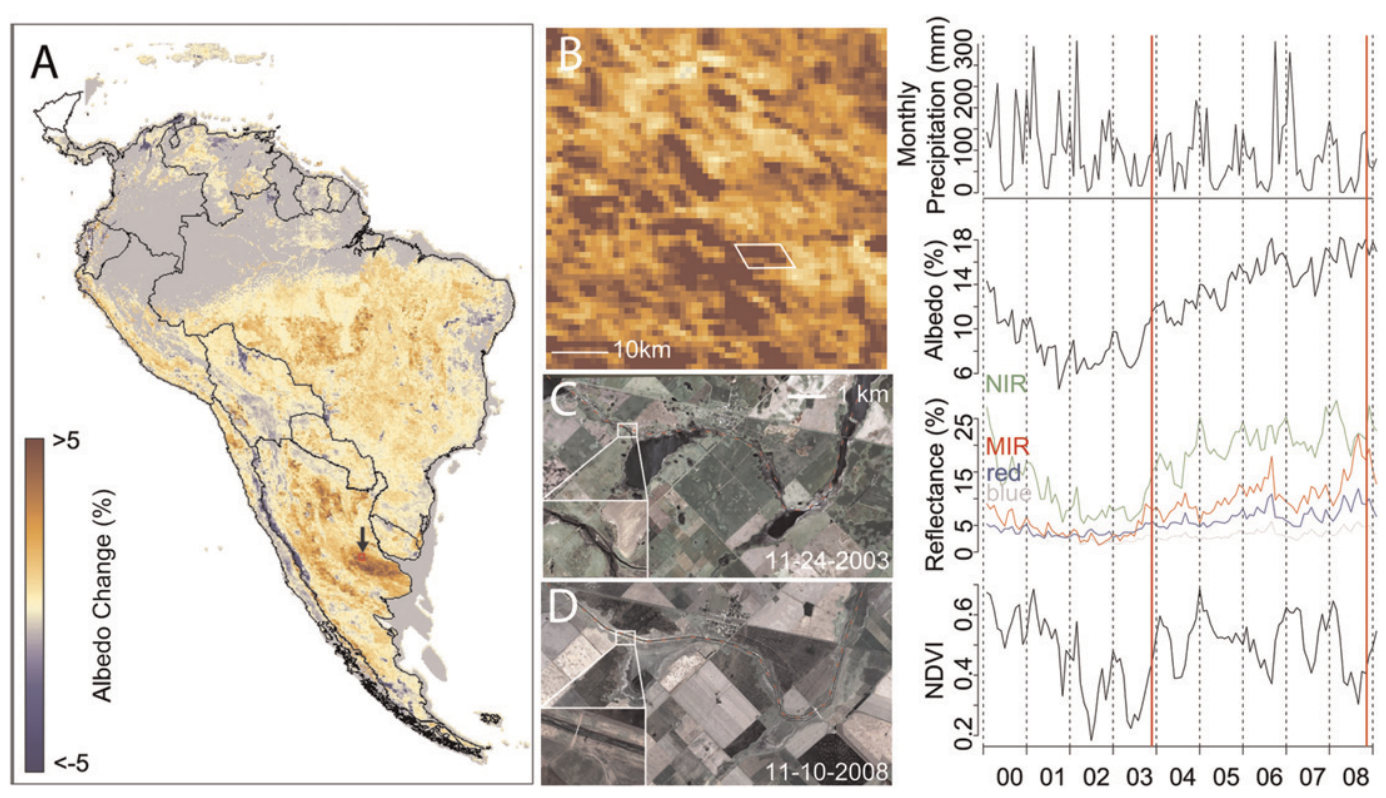

Figure 5. An example of changing surface water near El Dorado, Buenos Aires, Argentina $\left(-34.65^{\circ} \mathrm{S},-61.58^{\circ} \mathrm{W}\right)$ and the possible contributions of precipitation and canals. (a),(b) Change in albedo for an example landscape in the Buenos Aires region of Argentina. Gray areas mask low quality data. Insets show Quickbird images taken on (c) 24 Nov 2003 and (d) 10 Nov 2008. The dashed red line indicates a canal shown in the insets. Graphs are monthly precipitation $(\mathrm{mm})$, albedo (\%), percent reflectance, and NDVI averaged across the inset. Annual averages of monthly precipitation are in blue. Vertical red bar encompasses the interval between (c) and (d).

Our results show that albedo decreases are more common than albedo increases in the Southern Andes. This is consistent with the signature of melting snow from global warming. However, we caution that data from this region are prone to cloudmasking errors (Hall and Riggs 2007). Like snow, precipitation can alter albedos either indirectly by increasing vegetation cover or directly through changes in surface water. In places where snow and precipitation have changed, the 9-yr time period was not long enough to distinguish natural weather variability from directional trends from climate change. Likewise, because the areas with low quality data that we ignored are primarily in wetter cloudier areas in the northern portion of the continent, our analysis is biased toward albedo changes in more arid areas. It is possible that there were large albedo changes in these areas that we did not observe.

This study shows the key role that surface water plays in driving continentalscale albedos. The spatial extent of large albedo increases in the Santa Fe and Buenos Aires regions is greater than the arc of deforestation. In most climate models, surface albedo is modeled in a coupled land model such as the Common Land Model (Dai et al. 2003). Surface albedo is represented as a mixture of soil and vegetation albedos, each with intrinsic albedos that vary by vegetation and soil 


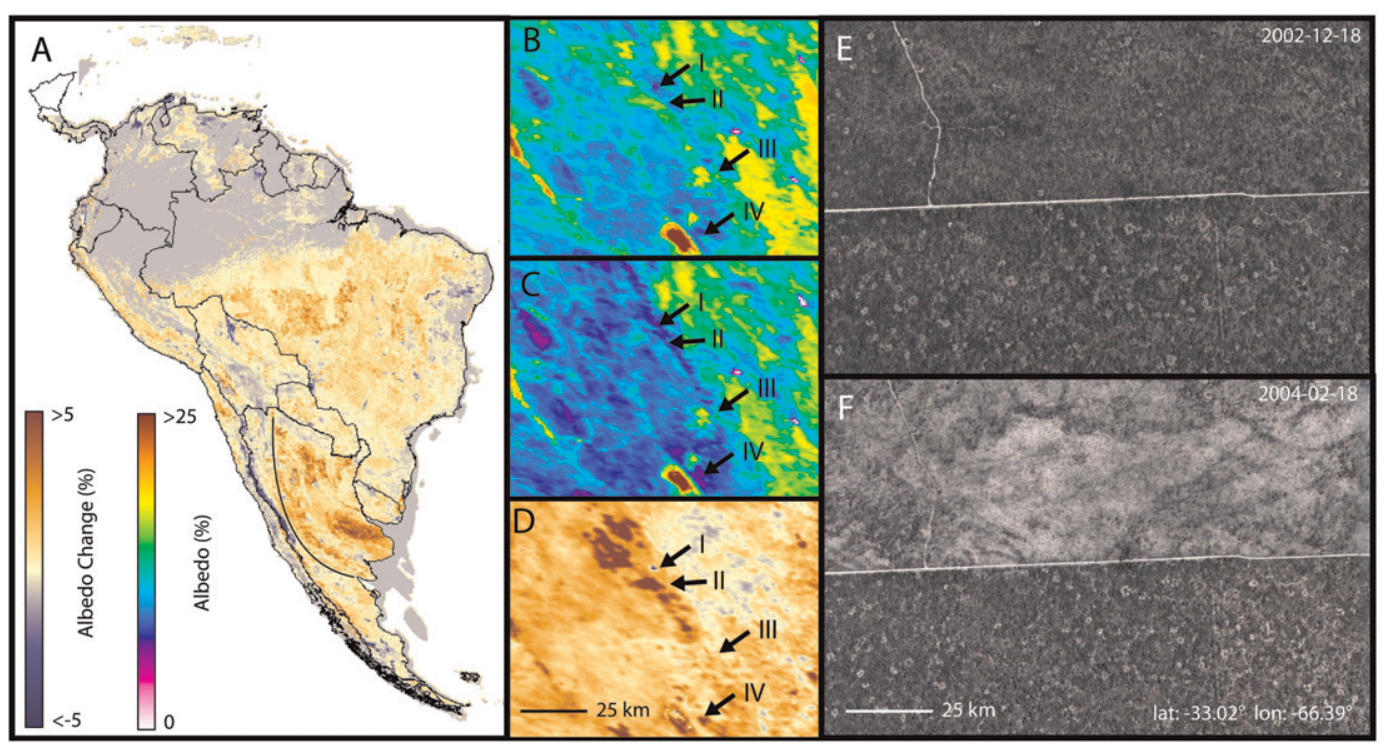

Figure 6. An example of albedo increases from land-cover change in arid regions. (a) Change in albedo within a region of interest along the arid frontier (black arc) in Argentina. Gray areas mask low quality data. Albedo (\%) in the region in (b) 2000-02 and (c) 2006-08. (d) Arrows indicate four features: (i) a recent reservoir; (ii) a recent large albedo increase; (iii) the town of San Luis, Argentina; and (iv) a saline lake (Salinas del Bebedero). (e), ( $f$ ) Quickbird images accessed through Google Earth showing a close up of the recent increase in albedo (ii) resulting from a decrease in vegetative cover likely from grazing.

classes (Zeng 2001). To accommodate seasonal albedo variation, vegetation varies is seasonally modulated by estimates of leaf area index (LAI) and soil albedo is modulated by modeled soil moisture (Wei et al. 2001; Yang and Dickinson 1996; Zeng et al. 2002). Minimum albedos thus result when LAIs are lowest (dry season) and soil moistures are highest (wet season). In the Common Land Model, minimum albedos theoretically possible in the Buenos Aires and Santa Fe regions of Argentina are $8 \%$ when the dark soils are fully saturated (Dai et al. 2003; Post et al. 2000) and the contribution of vegetation classed as croplands (19\%) is canceled by vanishing LAI (Dai et al. 2003). We found that minimum albedos (5\%) in this region result from areas completely flooded by surface water (see supplementary Figure S7). Furthermore, flooding removes the contribution of vegetation even during the wet season when LAI is thought to be high. Because of the dominant role of surface water in shaping continental-scale albedo dynamics, efforts to incorporate more complex hydrological processes into land models is a priority toward improving climate models (Cresswell et al. 1993; Stanhill et al. 1968). Such a surface water process model might be analogous to current snow cover models, which extend the representation of albedo as a combination of contributions from soil and vegetation. Efforts to compare modeled albedo with MODIS observations did not report large discrepancies in the Buenos Aires and Santa Fe areas (Oleson 


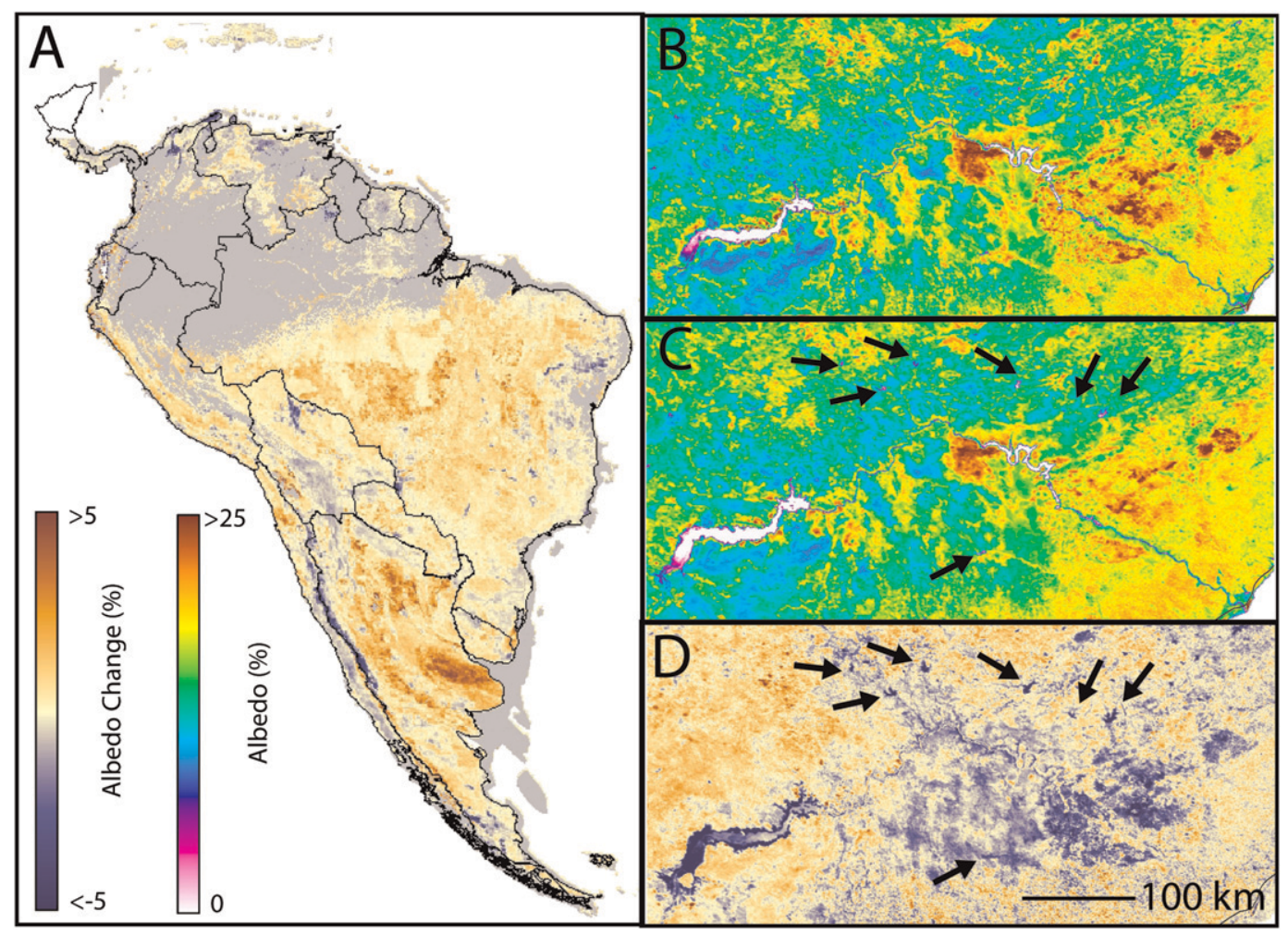

Figure 7. An example of albedo decreases associated with reservoirs in arid regions. Gray areas mask low quality data. (a) Change in albedo in a region of interest near the Sobradinho Dam in Brazil. Lake Sobradinho is the large reservoir on the left side of the region on the São Francisco River. Albedo (\%) in the region in (b) 2000-02 and (c) 2006-08. The arrows indicate seven new reservoirs. (d) Albedo decreases downstream of the reservoirs.

et al. 2003; Wang et al. 2004). However, these comparisons were not based on albedo dynamics over time periods longer than a single year.

Beyond identifying surface water as a driver of albedo changes, we were unable to distinguish the role of natural variation in flooding from changing human infrastructure in shaping these patterns. In the Santa Fe and Buenos Aires regions, there were more large flooding events earlier in the 9-yr time series, particularly in 2003 (NCDC 2009), than later in the study period. It is therefore likely that the broad pattern of decreasing surface water is driven by decreasing precipitation. However, the change in precipitation over the 9 -yr period has been relatively small. This weak correlation may illustrate the complex lags and processes that translate precipitation into surface water flooding that are poorly captured by precipitation rate alone. In places, we observed albedo increases from dissipating surface water even while precipitation continues to fall locally.

It is also possible that land-cover changes that manipulate the hydrological cycle such as dams and canals are widespread throughout the Santa Fe and Buenos Aires regions have contributed to the observed decreases in surface water. Unfortunately, 
the lack of a spatially and temporally explicit, independent dataset of land-use change analogous to the Brazilian PRODES dataset across Argentina makes quantifying potential relationships difficult. In the Santa Fe and Buenos Aires regions, recent land-use changes have occurred within finescale mosaics of sub-kilometerscale agricultural parcels or include small manipulations to the hydrological system such as dams, canals, and wells. Coordinating high spatial and temporal resolution data will help map such finescale land-cover changes (Loarie et al. 2007) and connect large-scale patterns to small-scale drivers (Baldi et al. 2008).

Without such an analysis, linking surface water changes to specific land-use changes is tenuous. Nevertheless, large dams in the Santa Fe region such as the Yacyretá Dam (Figure 2) and numerous smaller dams and levees have attempted to increase predictability to the flow of the Parana River and reduce the frequency of catastrophic floods. Studies have shown that the Yacyretá Dam, a three-decade hydroelectric project started in 1970, has significantly altered groundwater inflow into the Ibera wetlands (Canziani et al. 2006). In the Buenos Aires region, farmers traditionally alternated between summer crops and winter pasture (Solbrig 1997). The latter readily accommodated seasonal flooding. Increasingly, farmers have attempted to grow summer and winter crops (Martínez et al. 2005). Canals meant to prevent the accumulation of surface water in the winter have become increasingly widespread. Under such circumstances, flooding would become less frequent while precipitation regimes remain relatively constant.

The interaction between dams and albedo change can be complex. Throughout South America, the construction of dams is consistently accompanied by a local decrease in albedo from the newly flooded reservoir. Downstream of the reservoir, a much larger area may be affected by altered water flows. The Yacyretá Dam is upstream of a natural, low-albedo wetland that has increased in albedo in recent years. Other reservoirs, such as the Sobradinho Dam in Brazil, are upstream of arid landscapes with bright soils. In these arid landscapes, more predictable water supplies downstream of reservoirs may allow the expansion of darker agriculture causing a decrease in albedo.

The Pantanal in Brazil and Beni Savanna in Bolivia are large natural wetlands with albedos similar in magnitude to those of the Ibera wetlands in Santa Fe, Argentina, from 2000 to 2003. Unlike the Ibera wetlands, the Pantanal and Beni Savanna are not directly downstream of major dams, and their albedos decreased over the last decade. The Beni Savanna is located in the center of one of Integrated Regional Infrastructure for South America's (IIRSA) anchor projects. The proposal to transform the Madre de Dios-Beni-Mamoré-Itenez-Madeira river system into a major corridor for energy production and raw material export includes the construction of four hydroelectric dams (Kileen 2007). In July 2007, the Brazilian government authorized two dams (Antentas 2009) with a reported of investment of 1.26 billion U.S. dollars. The financing of one of these is under implementation (see online at http://www.iirsa.org). It is possible that these dams will alter surface water and have a large impact on local albedo.

Overall, our analysis of MODIS albedo highlights the importance of land-cover change and surface water in shaping albedo patterns (Feddema et al. 2005). In addition to modeling albedo changes from moist tropical deforestation, we must improve our ability to model surface water changes and complex albedo changes from agricultural expansion in arid areas. The mechanisms that drive landscape 
Earth Interactions • Volume 15 (2011) • Paper No. 7 • Page 14

level land-cover and surface water changes can be small scale and difficult to identify. Ensuring the continued coverage with high quality sensors with appropriate spatial and temporal resolutions will be critical toward increasing our understanding of these mechanisms (Nemani and Running 1995).

Acknowledgments. This work was made possible through the support of the Stanford University Global Climate and Energy Project.

\section{References}

Antentas, J. M., 2009: The Madeira River complex: Socio-environmental impact in Bolivian Amazonia and social resistance. Capitalism Nat. Socialism, 20, 12-20.

Baldi, G., M. D. Nosetto, R. Aragón, F. Aversa, J. M. Paruelo, and E. G. Jobbágy, 2008: Long-term satellite NDVI data sets: Evaluating their ability to detect ecosystem functional changes in South America. Sensors, 8, 5397-5425.

Betts, R. A., 2000: Offset of the potential carbon sink from boreal forestation by decreases in surface albedo. Nature, 408, 187-190.

Bonan, G. B., 2008: Forests and climate change: Forcings, feedbacks, and the climate benefits of forests. Science, 320, 1444-1449.

Canziani, G. A., R. M. Ferrati, C. Rossi, and D. Ruiz-Moreno, 2006: The influence of climate and dam construction on the Ibera wetlands, Argentina. Reg. Environ. Change, 6, 181-191.

Costa, M. H., S. N. M. Yanagi, P. J. O. P. Souza, A. Ribeiro, and E. J. P. Rocha, 2007: Climate change in Amazonia caused by soybean cropland expansion, as compared to caused by pastureland expansion. Geophys. Res. Lett., 34, L07706, doi:10.1029/2007GL029271.

Cresswell, H. P., D. J. Painter, and K. C. Cameron, 1993: Tillage and water content effects on surface soil hydraulic properties and shortwave albedo. Soil Sci. Soc. Amer. J., 57, 816-816.

Dai, Y., and Coauthors, 2003: The common land model. Bull. Amer. Meteor. Soc., 84, 1013-1023.

Feddema, J. J., K. W. Oleson, G. B. Bonan, L. O. Mearns, L. E. Buja, G. A. Meehl, and W. M. Washington, 2005: The importance of land-cover change in simulating future climates. Science, 310, 1674-1678.

Hall, D., and G. Riggs, 2007: Accuracy assessment of the MODIS snow products. Hydrol. Processes, 21, 1534-1547.

Hansen, M. C., and Coauthors, 2008: Humid tropical forest clearing from 2000 to 2005 quantified by using multitemporal and multiresolution remotely sensed data. Proc. Natl. Acad. Sci. USA, 105, 9439-9444.

Henderson-Sellers, A., and M. F. Wilson, 1983: Surface albedo data for climatic modeling. Rev. Geophys., 21, 1743-1778.

INPE, cited 2009: PRODES: Assessment of deforestation in Brazilian Amazonia. Instituto Nacional de Pesquisas Espaciais. [Available online at http://www.obt.inpe.br/prodes/.]

Jin, Y., C. B. Schaaf, C. E. Woodcock, F. Gao, X. Li, A. H. Strahler, W. Lucht, and S. Liang, 2003: Consistency of MODIS surface bidirectional reflectance distribution function and albedo retrievals: 2. Validation. J. Geophys. Res., 108, 4159, doi:10.1029/2002JD002804.

Kileen, T. J., 2007: A Perfect Storm in the Amazon Wilderness: Development and Conservation in the Context of the Initiative for the Integration of the Regional Infrastructure of South America (IIRSA). Advances in Applied Biodiversity Science Series, Vol. 7, Center for Applied Biodiversity Science, 102 pp.

Lambin, E. F., and Coauthors, 2001: The causes of land-use and land-cover change: Moving beyond the myths. Global Environ. Change, 11, 261-269.

Liang, S., and Coauthors, 2002: Validating MODIS land surface reflectance and albedo products: Methods and preliminary results. Remote Sens. Environ., 83, (1-2), 149-162. 


\section{Earth Interactions • Volume 15 (2011) • Paper No. 7 • Page 15}

Loarie, S. R., L. N. Joppa, and S. L. Pimm, 2007: Satellites miss environmental priorities: A response to Loveland et al. and Kark et al. Trends Ecol. Evol., 23, 183-184.

— G. G. Asner, and C. B. Field, 2009: Boosted carbon emissions from Amazon deforestation. Geophys. Res. Lett., 36, L14810, doi:10.1029/2009GL037526.

Martinelli, L. A., and S. Filoso, 2008: Expansion of sugarcane ethanol production in Brazil: Environmental and social challenges. Ecol. Appl., 18, 885-898.

Martínez, G. A., P. Laterra, and N. Maceira, 2005: Remote sensing assessment of Paspalum quadrifarium grasslands in the Flooding Pampa, Argentina. Rangeland Ecol. Manage., 58, 406-412.

Morton, D. C., R. S. DeFries, Y. E. Shimabukuro, L. O. Anderson, E. Arai, F. del Bon EspiritoSanto, R. Freitas, and J. Morisette, 2006: Cropland expansion changes deforestation dynamics in the southern Brazilian Amazon. Proc. Natl. Acad. Sci. USA, 103, 14 637-14 641.

NCDC, cited 2009: Global hazards and significant events, April 2003. National Climatic Data Center. [Available online at http://www.ncdc.noaa.gov/oa//climate/research/2003/apr/hazards.html.]

Nemani, R. R., and S. W. Running, 1995: Satellite monitoring of global land cover changes and their impact on climate. Climatic Change, 31, 395-413.

Oleson, K. W., G. B. Bonan, C. Schaaf, F. Gao, Y. Jin, and A. Strahler, 2003: Assessment of global climate model land surface albedo using MODIS data. Geophys. Res. Lett., 30, 1443, doi:10.1029/2002GL016749.

Olson, D. M., and Coauthors, 2001: Terrestrial ecoregions of the world: A new map of life on Earth. Bioscience, 51, 933-938.

Otterman, J., 1977: Anthropogenic impact on the albedo of the Earth. Climatic Change, 1, 137-155.

— desert. J. Appl. Meteor., 24, 228-235.

Post, D. F., A. Fimbres, A. D. Matthias, E. E. Sano, L. Accioly, A. K. Batchily, and L. G. Ferreira, 2000: Predicting soil albedo from soil color and spectral reflectance data. Soil Sci. Soc. Amer. J., 64, 1027-1034.

Sicart, J. E., P. Ribsten, P. Wagnon, and D. Brunstein, 2001: Clear-sky albedo measurements on a sloping glacier surface: A case study in the Bolivian Andes. J. Geophys. Res., 106, (D23), $31729-31737$.

Solbrig, O. T., 1997: Towards a sustainable Pampa agriculture: Past performance and prospective analysis. Harvard University David Rockefeller Center for Latin American Studies Rep., $52 \mathrm{pp}$. [Available online at http://www.drclas.harvard.edu/files/96-97-6.pdf.].

Stanhill, G., J. T. H. Cox, and S. Moreshet, 1968: The effect of crop and climatic factors on the radiation balance of an irrigated maize crop. J. Appl. Ecol., 5, 707-720.

Tian, Y., R. E. Dickinson, L. Zhou, R. B. Myneni, M. Friedl, C. B. Schaaf, M. Carroll, and F. Gao, 2004: Land boundary conditions from MODIS data and consequences for the albedo of a climate model. Geophys. Res. Lett., 31, L05504, doi:10.1029/2003GL019104.

Turner, B. L, II., E. F. Lambin, and A. Reenberg, 2007: The emergence of land change science for global environmental change and sustainability. Proc. Natl. Acad. Sci. USA, 104, $20666-$ 20671.

Wang, Z., X. Zeng, M. Barlage, R. E. Dickinson, F. Gao, and C. B. Schaaf, 2004: Using MODIS $\mathrm{BRDF}$ and albedo data to evaluate global model land surface albedo. J. Hydrometeor, 5, 3-14.

Wei, X., A. N. Hahmann, Z. L. Yang, X. Zeng, K. J. Schaudt, R. E. Dickinson, C. B. Schaaf, and N. Strugnell, 2001: Comparison of albedos computed by land surface models and evaluation against remotely sensed data. J. Geophys. Res., 106, (D18), 20 687-20 701.

Wielicki, B. A., T. Wong, N. Loeb, P. Minnis, K. Priestley, and R. Kandel, 2005: Changes in Earth's albedo measured by satellite. Science, $\mathbf{3 0 8}, 825$.

Xiao, X., S. Boles, S. Frolking, C. Li, J. Babu, W. Salas, and B. Moore, 2006: Mapping paddy rice agriculture in South and Southeast Asia using multi-temporal MODIS images. Remote Sens. Environ., 100, 95-113. 
Yang, Z. L., and R. E. Dickinson, 1996: Description of the Biosphere-Atmosphere Transfer Scheme (BATS) for the Soil Moisture Workshop and evaluation of its performance. Global Planet. Change, 13, (1-4), 117-134.

Zeng, X., 2001: Global vegetation root distribution for land modeling. J. Hydrometeor, 2, 525-530. _, M. Shaikh, Y. Dai, R. E. Dickinson, and R. Myneni, 2002: Coupling of the Common Land Model to the NCAR Community Climate Model. J. Climate, 15, 1832-1854.

Earth Interactions is published jointly by the American Meteorological Society, the American Geophysical Union, and the Association of American Geographers. Permission to use figures, tables, and brief excerpts from this journal in scientific and educational works is hereby granted provided that the source is acknowledged. Any use of material in this journal that is determined to be "fair use" under Section 107 or that satisfies the conditions specified in Section 108 of the U.S. Copyright Law (17 USC, as revised by P.IL. 94-553) does not require the publishers' permission. For permission for any other from of copying, contact one of the copublishing societies. 